\title{
A Beleza e a Feminilidade: Um Olhar Psicanalítico
}

Beauty and Femininity: A Psychoanalytic View

La Belleza y La Femineidad: Una Mirada Psicoanalítica
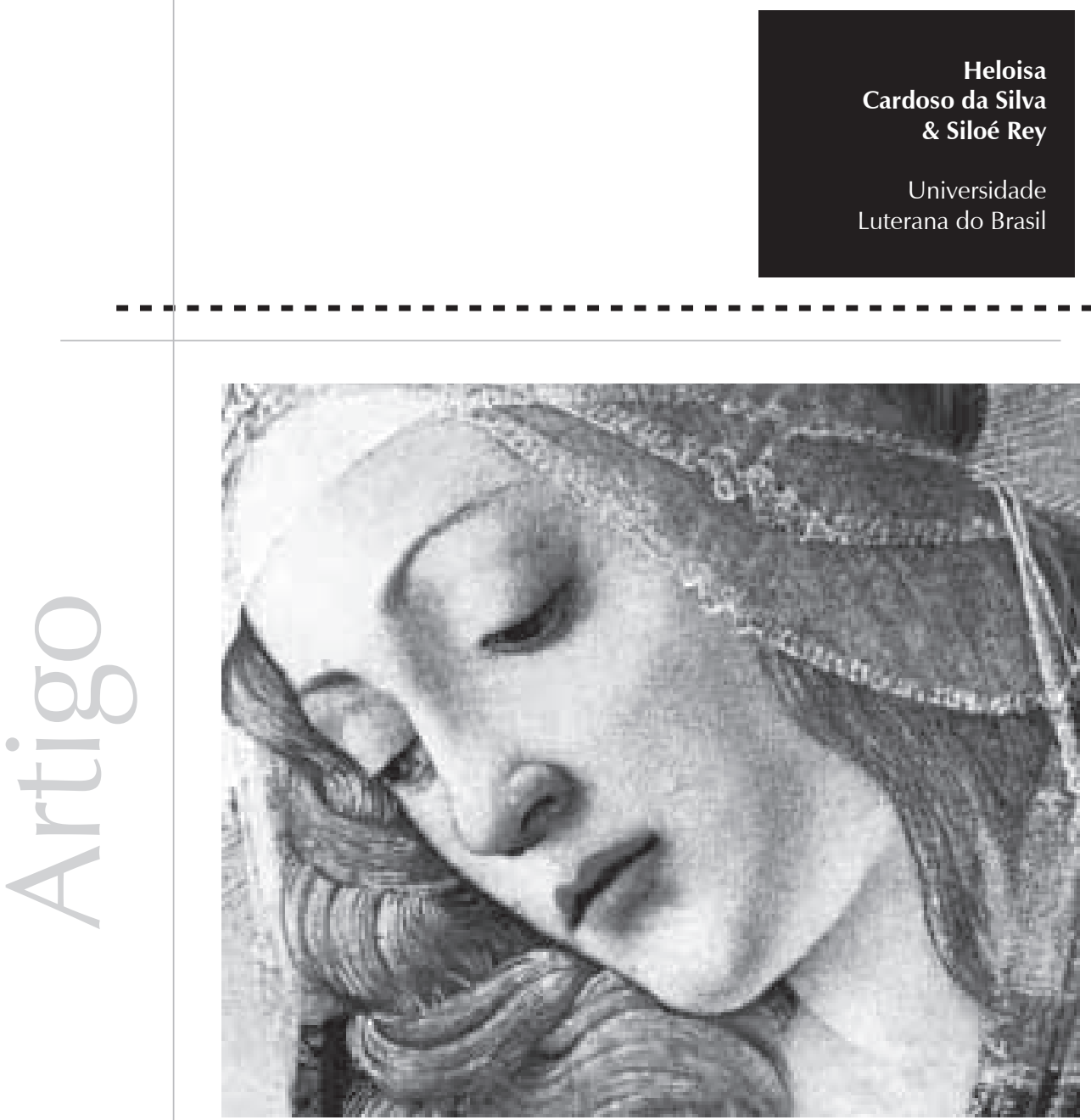
Resumo: O presente artigo refere-se a um estudo sobre os temas ideal de beleza e feminilidade, buscando investigar qual a possível função psíquica que os ideais de beleza veiculados na cultura exercem na constituição do feminino. Sendo um estudo histórico-conceitual, realizou-se uma pesquisa bibliográfica acerca da estruturação da feminilidade para a psicanálise e da relação da mulher com os ideais de beleza desde a Idade Média até a contemporaneidade. A partir das reflexões despertadas, pode-se dizer que a função que o ideal de beleza exerce na estruturação da feminilidade está relacionada à experiência singular de constituição psíquica, determinando a relação que a mulher estabelece com esse ideal. Se for profícua, a beleza pode ser concebida como uma das saídas da feminilidade, como forma de elaboração da castração. Contudo, se for escravizante, a beleza parece ser uma tentativa de encobrir a falta, em uma recusa à castração. Supõe-se, nesse caso, a existência de um conflito inconsciente relacionado a uma falha na constituição do eu ideal, e, a partir de uma imagem idealizada, busca-se atrair o olhar do outro, representado pelo olhar materno.

Palavras-Chave: Traços da Personalidade. Castração. Feminilidade. Psicanálise.

Abstract: This article refers to a study on the themes of ideal beauty and femininity in order to investigate what is the possible psychic function that the ideals of beauty in culture have served in the constitution of the feminine. As a historical and conceptual study, it was carried out a literature search on the structuring of femininity in psychoanalysis and the relation of women to the ideals of beauty since the Middle Ages until the present. From the reflections aroused, we can say that the function the ideal of beauty has on the structuring of femininity is related to the singular experience of the psychic constitution, determining the relationship that women set up with that ideal. If fruitful, beauty can be conceived as one of the ways femininity elaborates castration. However, if enslaving, beauty seems to be an attempt to cover the absence, a refusal to castration. It is assumed in this case the existence of an unconscious conflict related to a flaw in the constitution of the ideal ego and, from an idealized image, women seek to attract the gaze of another, which is represented by the maternal gaze.

Keywords: Personality traits. Castration. Femininity. Psychoanalysis.

Resumen: El presente artículo hace referencia a un estudio acerca de los temas ideales de belleza y femineidad, buscando investigar cuál es la posible función psíquica que los ideales de belleza enumerados en la cultura ejercen en la constitución de lo femenino. Por ser un estudio histórico-conceptual, se ha llevado a cabo una investigación bibliográfica acerca de la estructuración de la femineidad para el psicoanálisis y de la relación de la mujer con los ideales de belleza desde la Edad Media hasta la contemporaneidad. A partir de las reflexiones despertadas, se puede decir que la función que lo ideal de belleza ejerce en la estructuración de la femineidad está relacionada a la experiencia singular de constitución psíquica, determinando la relación que la mujer establece con ese ideal. Si es proficua, la belleza puede ser concebida como una de las salidas de la femineidad, como forma de elaboración de la castración. Sin embargo, si torna a la persona esclava, la belleza parece ser un intento de encubrir la falta, rehusando la castración. Se supone, en ese caso, la existencia de un conflicto inconsciente relacionado a una falla en la constitución del yo ideal y, a partir de una imagen idealizada, se busca atraer la mirada del otro, representado por la mirada materna. Palabras clave: Rasgos de personalidad. Castración. Femineidad. Psicoanálisis.

O presente artigo refere-se a uma pesquisa sobre a relação entre os ideais de beleza culturais e a constituição da feminilidade. Seu objetivo principal é debater essa temática a partir de um viés psicanalítico, tendo como problema central o seguinte ponto: qual a possível função psíquica exercida pelos ideais de beleza propagados na cultura ocidental contemporânea sobre a constituição do feminino?

A fim de discutir essa questão, buscouse compreender como se estrutura a feminilidade investigando-se a associação histórico-cultural entre a beleza e o feminino, o que levou à reflexão sobre os fenômenos sociais associados ao culto ao corpo ideal na contemporaneidade.

Para o desenvolvimento do trabalho, foi realizada uma pesquisa bibliográfica conforme as etapas propostas por Gil (2010), seguindo um caráter exploratório e uma abordagem qualitativa. Pertencendo ao campo psicanalítico, este estudo também se caracteriza por ser uma pesquisa históricoconceitual, aplicada em trabalhos que enfatizam a teoria psicanalítica, e que tem o objetivo de estudar a construção dos seus conceitos. Nesse processo, utiliza-se 
o material bibliográfico já elaborado e reescreve-se, conforme a temática, o perfil do fenômeno pesquisado, a fim de aprimorar os conceitos já estabelecidos e favorecer a sua compreensão teórica (Mezan, 1994).

Ao se observar o cenário social da atualidade, é fácil perceber que há um grande movimento, especialmente por parte das mulheres, em busca de um ideal de perfeição estética, fundamentado em um culto ao corpo belo e perfeito. A partir desse fenômeno, surgem diversas consequências, dentre as quais se pode citar o consumo de produtos cosméticos.

Embora a economia brasileira ocupe o $11^{\circ}$ lugar no ranking mundial, o País é o sexto maior mercado nos negócios desses produtos. Além disso, apesar de o PIB nacional ter crescido $7,5 \%$, os serviços relacionados à indústria da beleza cresceram 47\% (Godoi, 2006).

Em nossos dias, a identidade do corpo das mulheres equivale à harmonia entre a tríade belezasaúde-juventude. Influenciadas especialmente pela cultura midiática, cada vez mais elas estão se colocando a serviço de seus corpos, sendo incitadas a

identificar a sua beleza com juventude e juventude com saúde (Del Priori, 2009).
Outro ponto importante diz respeito à realização de cirurgias plásticas, pois, segundo Godoi, o Brasil fica atrás apenas dos Estados Unidos nessa questão. De acordo com uma pesquisa realizada pela Sociedade Brasileira de Cirurgia Plástica - SBCP (2009), entre setembro de 2007 e agosto de 2008, foram realizadas aproximadamente $629 \mathrm{mil}$ cirurgias plásticas no País por profissionais habilitados. Dentre elas, 73\% eram estéticas, sendo que $88 \%$ das pessoas que a elas se submeteram são do sexo feminino.

Conforme a pesquisa mencionada, as intervenções estéticas mais realizadas são de aumento de mama (21\%), lipoaspiração (20\%) e abdômen (15\%), seguidas da redução de mama (12\%), pálpebras (9\%), nariz e plástica de face (7\% cada). Quanto aos procedimentos não cirúrgicos, os mais realizados são os preenchimentos e a aplicação de toxina botulínica (91\%).

Essa questão é bastante instigante quando se observam as diferentes formas que a estética do corpo vem assumindo para as mulheres na atualidade, exigindo delas uma certa aparência. Pode-se perceber isso quando tais configurações ligam às formas de seus corpos várias expressões populares, tais como:

\section{(...) ser sensualmente feminina, ser desejada, ser olhada, cuidar de si, gostar-se mais, ter um corpo ideal, ter o corpo que sempre sonhou, dentre muitas outras denominações que, implicitamente, pedem e prometem a inserção num espaço de idealização da imagem do corpo feminino a ser imediatamente alcançada (Souza, 2007, p. 14, itálicos do autor)}

Ao mesmo tempo em que as diversas formas de intervenções estéticas se mostram como um meio de acesso ao ideal de beleza, por outro lado, revelam-se como uma via de entrada a várias configurações de inquietações psíquicas, nas quais o corpo parece expressar, simultaneamente, a chave e o enigma dessas questões. Isto é, "paralelo ao investimento em uma imagem de corpo feminino ideal, valendo-se dos recursos que a ciência dispõe para moldá-lo, ele - o corpo - parece ter se tornado o palco de muitos conflitos e questionamentos" (Souza, 2007, pp. 14-15).

Em nossos dias, a identidade do corpo das mulheres equivale à harmonia entre a tríade beleza-saúde-juventude. Influenciadas especialmente pela cultura midiática, cada vez mais elas estão se colocando a serviço de seus corpos, sendo incitadas a identificar a sua beleza com juventude e juventude com saúde (Del Priori, 2009).

No século XX, os meios midiáticos contribuíram para legitimar essa tríade, reforçando a concepção de que as formas redondas, antigamente associadas à saúde, agora não são bem vistas, constituindo um novo critério de feiura. Dessa forma, devido à hegemonia das imagens, "instaurou-se a tirania da perfeição física. Hoje, todas querem ser magras, leves, turbinadas (...). Todas as mulheres parecem participar da sinfonia do corpo magnífico, quase atualizando as intolerantes teses estéticas nazistas" (Del Priori, 2009, p. 79). 
Nesse sentido, é importante interrogar:

Por que essa necessidade de perfeição? A ilusão nos provoca mais frustrações que prazer? Não será esse tipo de imagem que leva milhares de mulheres a se submeterem à tortura de uma operação plástica, a continuarem frustradas, umas mais, outras menos, com seus corpos reais, mesmo depois da transformação? (Del Priori, 2009, p. 88)

Dessa forma, diante de tais indagações, fazse necessária uma reflexão crítica frente a essas questões que surgem e se propagam na cultura e, por conseguinte, influenciam diretamente na subjetivação não só das mulheres mas também de todos os seres humanos.

\section{A feminilidade}

O campo da feminilidade, no decorrer dos estudos psicanalíticos a partir de Freud, foi e vem sendo investigado, especialmente por seu caráter inacabado, obscuro e enigmático.

No seu texto Feminilidade, Freud (1932/2006f) salientou que a psicanálise não busca fazer a descrição do que é uma mulher, pois esse seria um trabalho difícil de ser feito, embora procure investigar como é sua formação, desenvolvimento e constituição psíquica.

De acordo com Valdivia (1997), "a questão da especificidade do feminino constitui o ponto de partida da psicanálise e também o ponto de retorno constante à teoria freudiana" (p. 20), ou seja, ao longo da elaboração da sua teoria e obras, a concepção de Freud a respeito da mulher e de sua sexualidade é paulatinamente reconstruída. Ao mesmo tempo, apesar de tais modificações, suas descobertas acerca da feminilidade foram importantíssimas e definitivas, no sentido de que os demais autores se basearam e se baseiam nelas (Silva \& Folberg, 2008).

Nos Três Ensaios Sobre a Teoria da Sexualidade, Freud (1905/2006a) apresenta sua primeira teoria sexual com a hipótese de que tanto o menino como a menina reconhecem apenas o órgão sexual masculino, isto é, o pênis no menino e o clitóris na menina como seu correspondente; emerge, portanto, o complexo de castração em ambos os sexos e a inveja do pênis na menina.

Mais tarde, em A Organização Genital Infantil, Freud (1923/2006b), após suas observações e experiências, complementa essa ideia concluindo que existem diferenças na organização da sexualidade infantil e adulta, sendo esta genital, e aquela, fálica. Assim, até a puberdade, período em que a fase genital se desenvolve, a vagina não é descoberta.

Em A Dissolução do Complexo de Édipo, o autor diferencia o curso no desenvolvimento da sexualidade tomado por meninos e meninas. Enquanto o complexo de castração para o menino implicará o declínio do complexo de Édipo, na menina, ele será o promotor desse complexo, fazendo-a voltarse para o pai a fim de tentar substituir a falta do pênis. O desejo de ter um filho seu, como substituto do pênis, produzirá sua entrada no complexo de Édipo, sendo que, no decorrer do tempo, a menina se afastará do pai por não poder realizar tal desejo (Freud, 1924/2006c).

Em Algumas Consequências Psíquicas da Distinção Anatômica entre os Sexos, Freud (1925/2006d) postula que o reconhecimento da diferença sexual leva a menina à renúncia da masculinidade, dirigindo-se para a feminilidade. A decepção pela ausência do pênis a leva a afastar-se da mãe, substituindo o desejo de possuir o órgão masculino pelo de ter um filho do pai, voltando-se, portanto, para ele. Assim, a mãe torna-se uma rival, ao passo que a menina se torna mulher.

Reelaborando sua construção, Freud apresenta, em 1931, um novo pressuposto na tentativa de dar conta da constituição da feminilidade. A partir desse ponto, o autor passa a enfatizar a relação mãe-filha como ponto fundamental para a estruturação feminina. 
Considerando a relevância dessa ligação da menina com a figura materna, é importante abordar um texto elaborado por Freud (1914/2004) intitulado À Guisa de Introdução ao Narcisismo. Nesse artigo, o narcisismo, estruturado nesse momento inicial de vida, na relação com a figura materna, passa a ser concebido como condição fundamental à constituição subjetiva do sujeito, "chegando mesmo a se confundir com o próprio eu" (Garcia-Roza, 2008, p. 42).

Ademais, há a introdução dos conceitos de eu ideal e de ideal de eu, considerados instâncias psíquicas fundamentais à constituição do sujeito. De acordo com Freud:

O amor por si mesmo que já foi desfrutado pelo Eu verdadeiro na infância dirige-se (...) a esse Eu ideal. O narcisismo surge deslocado nesse novo Eu que é ideal e que, como o Eu infantil, se encontra agora de posse de toda a valiosa perfeição e completude (1914/2004, p. 112)

Conforme Garcia-Roza, o eu não está instaurado desde o início, e será constituído "pelas enunciações, pelos juízos de valor, pelas declarações de preferência ou de rejeição" (p.

Situado no lugar do simbólico,

esse eu ideal se desdobra em outra instância, o ideal de eu. Este é algo externo ao sujeito, e referese a exigências às quais ele se esforçará para satisfazer, em uma promessa de restituir a perfeição narcísica perdida (Garcia-Roza, 2008).
57). E uma das formas que ele pode tomar é a de eu ideal, que é "(...) uma imagem do eu dotada de todas as perfeições, sobre o qual recai (...) o amor de si mesmo de que na infância gozou o eu real" (2008, p. 57).

O eu ideal constitui-se a partir das figuras parentais, que projetam no bebê uma imagem idealizada, fazendo ressurgir o seu próprio narcisismo - renunciado por exigência da realidade. Dito de outra forma, o eu ideal é efeito do discurso parental, que, por ser apaixonado, abdica de qualquer forma de consciência crítica para produzir uma imagem idealizada (Garcia-Roza, 2008).

Situado no lugar do simbólico, esse eu ideal se desdobra em outra instância, o ideal de eu. Este é algo externo ao sujeito, e refere-se a exigências às quais ele se esforçará para satisfazer, em uma promessa de restituir a perfeição narcísica perdida (Garcia-Roza, 2008).

\begin{abstract}
Como sempre, no campo da libido, o ser humano mostra-se aqui incapaz de renunciar à satisfação já uma vez desfrutada. Ele não quer privar-se da perfeição e completude narcísicas de sua infância. Entretanto, não poderá manter-se sempre nesse estado, pois as admoestações próprias da educação, bem como o despertar de sua capacidade interna de ajuizar, irão perturbar tal intenção. Ele procurará recuperá-lo então na nova forma de um ideal de Eu. Assim, o que o ser humano projeta diante de si como seu ideal é o substituto do narcisismo perdido de sua infância, durante a qual ele mesmo era seu próprio ideal (Freud, $1914 / 2004$, p. 112)
\end{abstract}

Dessa forma, essas instâncias psíquicas eu ideal e ideal de eu - são constituídas na relação inicial com as figuras materna e paterna, demandando um investimento destas para que possam ser instauradas. Nesse sentido, é importante retomar o texto freudiano Sexualidade Feminina, aludido anteriormente, no qual a relação mãe-filha ganha um lugar de destaque na feminilidade.

Essa ligação precede a ligação da menina com o pai; desse modo, a fase pré-edipiana feminina é demasiadamente importante. Por tal motivo, Freud (1931/2006e) passa a repensar a questão do complexo de Édipo feminino.

Há um processo bastante demorado até que a mulher chegue ao resultado final desse complexo. O reconhecimento da sua castração implica o reconhecimento da superioridade masculina e, por conseguinte, o da inferioridade feminina, o que a faz rebelarse contra esse estado de coisas indesejável. Dessa maneira, há três saídas clássicas para essa situação: a frigidez, por abandonar a atividade fálica e sua sexualidade em geral devido à insatisfação com seu clitóris, uma amarração ao complexo de masculinidade, mantendo a esperança de possuir um pênis com a fantasia de poder tornar-se homem no futuro, o que pode resultar em um comportamento homossexual, e a atitude feminina normal final, que seria tomar o pai 
como objeto para que, posteriormente, ele a conduza a uma escolha heterossexual (Freud, 1931/2006e).

Assim, percebe-se que a passagem pelo complexo de Édipo é que organizará a posição sexuada do sujeito, que, através das relações identificatórias, atravessará essa experiência que irá resultar em uma identificação feminina ou masculina.

Na conferência A Feminilidade, Freud (1932/2006f) orienta sua investigação no sentido de procurar desvendar o que põe fim ao vínculo da menina com a mãe, visto que a direção habitual é dar lugar a um vínculo com o pai. Esse passo não implica somente uma simples troca de objeto, e o afastamento da mãe é acompanhado por uma hostilidade que pode persistir e influenciar diretamente a relação mãe-filha por toda a vida.

É importante apontar aí que, contraditoriamente, nesse momento em que a menina mais hostiliza a mãe é que, ao mesmo tempo, ela deve abandoná-la como objeto de amor e tomá-la como objeto identificatório. Em outras palavras, é preciso conservá-la “(...) como modelo de identificação para ocupar uma posição feminina em relação ao pai, quando ela deveria ser abandonada como objeto de amor" (Lima, 2006, p. 41).

Por outro lado, nessa relação mãe-filha, há a posição do agente materno. De acordo com Freud (1925/2006d), a resolução para a feminilidade estaria na concepção de um filho como forma de obter o objeto fálico que Ihe falta. Isso pode levá-la à fantasia de que uma filha, por não tê-lo, não the proporcionaria ilusoriamente a plenitude fálica tão almejada e, portanto, não pode receber o investimento narcísico que um filho receberia.

Assim, de acordo com Freud (1932/2006f), o desenvolvimento da feminilidade sofre a influência dos "fenômenos residuais do período masculino inicial, (...) (os quais contribuem para a) expressão da bissexualidade" (p. 130) no transcorrer da vida de algumas mulheres. Assim, o caráter enigmático da feminilidade pode derivar disso.

Relendo o texto freudiano Análise Terminável e Interminável, de 1937, Nunes afirma que o autor repensa a problemática da castração e acha "repúdio da feminilidade a descrição correta dessa notável característica dos humanos" (2002, p. 55). Assim, constata que a feminilidade é uma característica comum a ambos os sexos e não apenas ao sexo feminino, enfatizando seu estatuto originário e universal e situando-a no âmago da cultura e, em consequência, do processo de estruturação subjetiva do ser humano, já que é uma experiência determinante para a sua constituição como sujeito sexuado.

Apontando uma concepção que prioriza a via do exercício pulsional e não apenas a das identificações edípicas, Poli afirma que a feminilidade corresponderia à posição de passividade pulsional, ao lado da atividade de cunho masculino. Dessa forma, tanto o homem como a mulher disporiam de ambas as tendências. A libido, sendo masculina, tem necessariamente o caráter de atividade na busca pela satisfação pulsional que a mobiliza. Até quando se goza da posição passiva fazendo-se de objeto para um Outro - se está diante de uma passividade produzida de forma ativa, portanto, "a feminilidade seria uma produção secundária da libido, resultado da reflexibilidade no percurso pulsional" (2007, p. 32).

A feminilidade indica a possibilidade de superação do pré-edípico pelo abandono da atividade pulsional e pela reconciliação com a posição passiva. Mas isso só é possível se a menina suporta desprender-se da mãe e, com ela, do erotismo clitoridiano. Não se trata exclusivamente de recalcar a atividade, mas de superá-la e substituí-la (Poli, 2007).

Após a frustração da menina nas relações com a mãe e o pai no complexo edípico, ocorre o processo de recalcamento para que ela não 
perca o amor dos pais. "A feminilidade surge, então, quando a menina reporta o pedido que faz ao pai a um outro homem, de quem esperava receber o pênis-bebê, isto é, quando ela retorna, de forma ativa, à posição passiva que a levou ao pai" (Poli, 2007, p. 35).

Enfim, o percurso teórico da concepção freudiana acerca da sexualidade feminina, apesar de sua incontestável relevância, não consegue abarcar toda essa questão e, em seu último texto sobre o tema, o autor considera a feminilidade um mistério, o que revela a incompletude de tal conceito.

Apesar de basear-se na teoria freudiana, Lacan construiu uma teoria própria a partir da releitura das obras de Freud. Dessa maneira, para se compreender sua concepção da feminilidade, faz-se necessário retomar seu entendimento do que seja o complexo de Édipo.

De acordo com Lacan (1958/1998c), ele se estrutura em três tempos, nos quais está em jogo a relação do sujeito com o falo. $\mathrm{O}$ primeiro tempo é chamado de etapa fálica primitiva, e nele

(...) o falo está presente na ordem da cultura, como pano de fundo. O desejo da mãe é orientado por ele, e a criança é submetida ao capricho materno; seu desejo é o desejo da mãe. Nesse tempo, a mãe é fálica, e a criança é o seu falo. A criança aí já está presente no desejo do Outro (mãe) (Valdivia, 1997, p. 25)

No segundo tempo do Édipo, de acordo com Lacan (1958/1998c), o pai intervém como privador da mãe em duplo sentido, enquanto priva a criança do seu objeto de desejo e enquanto priva a mãe de seu objeto fálico. E ele, o pai, vai aparecer mediado no discurso materno.

Nesse momento, existe a dialética do ser ou não ser o falo da mãe, e a criança só chegará a essa interrogação pessoal na medida em que o pai privador a faz pressentir que a mãe reconhece sua lei como aquilo que mediatiza o seu desejo, que não mais a criança, mas sim, o objeto que se supõe que o pai tenha (Dor, 2003).

No terceiro tempo do Édipo, conforme Lacan, diferentemente do pai onipotente e privador do segundo tempo, este se revela como aquele que "pode dar à mãe o que ela deseja e pode dar o que possui. Aqui intervém, portanto, a existência da potência no sentido genital da palavra - digamos que o pai é um pai potente" (1958/1998, p. 200).

Esse tempo, segundo Dor, "é marcado pela simbolização da lei, que atesta da melhor forma que a criança recebeu sua plena significação" (2003, p. 88). Assim, ele significa o declínio e a saída do Édipo, sendo que isso é favorável na medida em que é feita a identificação com o pai como aquele que tem o falo, identificação essa denominada ideal de eu (Lacan, 1958/1998c).

Nessa saída edípica, conforme Valdivia, a menina irá reconhecer o homem como aquele que detém o falo: "ela sabe onde está, onde deve ir buscá-lo" (1997, p. 26), isto é, ao lado do pai, aquele que o possui.

No seminário As Psicoses, Lacan (1956/1998b) afirma que a identificação da menina com a mãe se realiza através do desvio rastreado pelo objeto de desejo do pai, o que leva algumas mulheres a se identificarem imaginariamente com o pai, resultando esse processo em constituir a posição estrutural histérica. Nesta, assume-se a posição masculina, o que indica uma dificuldade de ordem sexual.

Assim, o corpo de outra mulher torna-se suporte de sua identificação imaginária na procura de suprir a falta de um reconhecimento simbólico paterno. Dito de outra forma há uma constante busca "(...) em seu semelhante do traço feminino que Ihe falta" (Valdivia, 1997, p. 26).

Assim, a feminilidade, é sempre mascarada e 


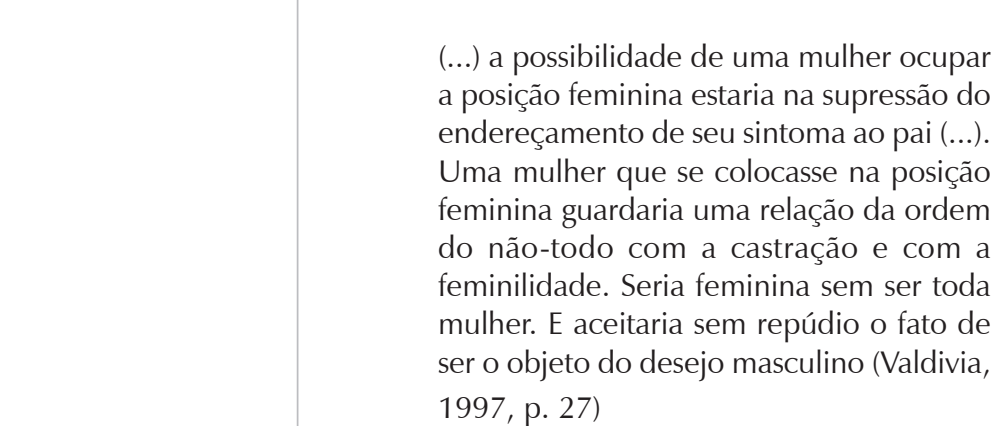

De acordo com Jerusalinsky (2000), a menina que acaba de se separar do corpo da mãe e de se instalar no lugar do Um buscará no olhar do Outro algo que a reconheça. Se esse Outro for a figura materna, ela tende a se reunificar no corpo materno. Se o olhar for o da figura paterna, esta poderá conceder-lhe uma versão imaginária do objeto que Ihe falta. Por tal motivo, a mulher depende do desejo do outro, não do Outro, mas do outro qualquer, e a feminilidade consiste em ter que suportar que o objeto que falta à mulher tem de vir desse outro qualquer, sendo ela obrigada, assim, a suportar a versão imaginária do objeto que o desejo do outro pendura em suas costas. Enfim, a mulher depende do olhar dos outros muito mais que o homem, no sentido de que ela tem que suportar, com seu corpo e em seu corpo, que o objeto que lhe falta venha do outro qualquer.

\section{De acordo com Novaes (2006), "historicamente, a imagem da mulher se justapõe à de beleza e, como segundo corolário, à de saúde (fertilidade) e juventude" (p.} 23).
Enfim, pode-se afirmar que os ideais femininos, como a maternidade - que anteriormente constituía o objetivo exclusivo da existência da mulher -, foram se modificando com as transformações históricas e socioculturais. Assim, nessa nova ordem social, passou a se atribuir valor à imagem, o que está relacionado a uma das possíveis formas de estruturação da feminilidade, que é a captura do olhar do outro. Portanto, promoveu-se uma mudança da relação da mulher não só com a sociedade mas também consigo própria, com seu corpo, e ela expressa por meio dele suas conquistas de maior liberdade e autonomia.

\section{A mulher e o ideal de beleza}

Na cultura ocidental contemporânea, há uma forte associação entre a figura da mulher e a beleza, a saúde e a juventude. Contudo, essa ligação vem se desenvolvendo ao longo da História.

Sendo o corpo palco de expressão da beleza feminina, primeiramente, é importante salientar que a concepção de corpo que permeia este trabalho é a de corpo psicanalítico, o qual encontra seu lugar não em uma anatomia apenas biológica, mas sim, em uma anatomia própria e singular, construída através "do cenário fantasmático de cada um. (Certamente) (...) encontramos nas manifestações objetivas do corpo biológico as ressonâncias desse outro corpo, portador de múltiplos sentidos e significações em função desse cenário fantasmático" (Fernandes, 2008, p. 85). Assim, é um corpo que transcende o somático e que está articulado com a história do sujeito.

De acordo com Novaes (2006), "historicamente, a imagem da mulher se justapõe à de beleza e, como segundo corolário, à de saúde (fertilidade) e juventude" (p. 23). Contudo, na contemporaneidade, tais representações parecem estar se manifestando intensamente.

Traçando uma breve história sobre a mulher e a beleza, Vilhena, Medeiros e Novaes dizem que, durante a Idade Média, a beleza feminina era vista como "armadilha do pecado, uma tentação do diabo (...), um encobrimento enganoso de uma essência impura, leviana e vil" (2005, p. 120).

No século XVI, enfatizava-se a parte superior do corpo, como a delicadeza da pele, a intensidade dos olhos, a simetria dos traços. Já nos séculos subsequentes, iniciou-se a valorização das partes inferiores, como pernas, quadris e cintura (Moreno, 2008).

Com acontecimentos e movimentos políticos importantes, que resultaram em maior participação social da mulher, o século XIX trouxe mudanças no que se refere à figura feminina: o seu corpo ganha mais liberdade e espaço no âmbito público. Com isso, "a 
beleza passa a sinalizar uma mulher mais autônoma, que trabalha e usufrui de uma liberdade conquistada e maior" (Moreno, 2008, p. 17).

Nesse século, a visão de beleza feminina estava relacionada à elegância, à posse de um corpo-ampulheta moldado por "espartilhos e anquinhas capazes de comprimir ventres e costas, projetando seios e nádegas. A couraça vestimentar deveria servir para protegê-las, simbolicamente, do desejo masculino" (Del Priori, 2009, p. 59),

No século XX, conforme Del Priori, com o desnudamento - na mídia e nas praias -estimulou-se o desvelamento do corpo feminino em público, ou seja, ele adquiriu mais liberdade, banalizando-se sexualmente. Com isso, a saída foi cobri-lo com cremes, vitaminas, silicones e colágenos. Assim, essa libertação feminina parece ter tomado um sentido diferente, tornando-se "sinônimo de lutar, centímetro por centímetro, contra a decrepitude fatal. Decrepitude, agora, culpada, pois o prestígio exagerado da juventude tornou a velhice vergonhosa" (2009, p. 11).

Ao mesmo tempo, nesse século, o olhar se torna mais agudo com a descoberta da celulite, em 1924, com a possibilidade de se eliminar rugas via cirurgia e de se mudar o corpo feminino, "que passa da sinuosidade de um $\mathrm{S}$ para a magreza e a postura de um I" (Moreno, 2008, p. 17).

Especialmente a partir da década de 60, preocupar-se com a beleza física deixou de ser um tabu, o que impulsionou o uso de cosméticos e a adesão às cirurgias plásticas, as quais deixaram de ser consideradas pecado ou desrespeito à obra divina (Sant'Anna, 2001).

Para Novaes, no início do século XX, "O corpo vai reunir o conjunto de discursos que hoje vemos vigorando, (sendo que, para a ciência, ele é) umas das peças centrais de aferição do dispositivo de civilização" (2006, p. 25) e as cirurgias estéticas, uma das medidas de avanço civilizatório. Tal concepção, portanto, corrobora as transformações ocorridas na área da beleza feminina.

É nesse contexto que Del Priori diz: "Sobre a cera dos corpos femininos, o século XXI vai imprimindo suas primeiras marcas. Produto social, produto cultural e histórico, nossa sociedade os fragmentou e recompôs, regulando seus usos, normas e funções" (2009, p. 9).

Vemos, portanto, que, na contemporaneidade, a concepção de beleza está relacionada à boa forma do corpo, a qual "(...) ocupa um lugar de destaque nos atuais modos de subjetivação, tornando-se assim um valor indispensável ao sujeito, que agrega à materialidade de seu corpo aquilo que possa conferir uma especial estima à sua dimensão física" (Souza, 2007, p. 27).

A busca pela beleza e juventude consiste em uma corrida infinita que atinge mulheres de todas as classes sociais. Ser bela significa, então, aproximar-se de um ideal determinado de maneira universal (Sant'Anna. 2001). Através dessas imagens idealizadas, as mulheres buscam ser amadas, enquanto, para os homens, tais imagens são objetos de desejo sexual (Ramalho, 2001).

E, apesar de muitas transformações terem ocorrido, inclusive na própria concepção de beleza, por mais que a cultura tenha proporcionado possibilidades identificatórias às mulheres, certos aspectos permanecem, como o ideal amoroso. E, juntos a esse, os ideais de beleza e de juventude vêm sendo difundidos na modernidade, "chegando muitas vezes a ser um imperativo, principalmente para as mulheres" (Ramalho, 2001, p. 42).

"Hoje, o que conta é a aparência. As imagens dos corpos que desfilam assumem a forma padronizada vigente e o lugar de objetos de desejo (...). São muitas as 
ofertas para a mulher parecer diferente, mais bonita, mais desejável e ilusoriamente perfeita" (Pimentel, 2008, p. 43)

Enfim, como salienta Ramalho (2001), vive-se na era das imagens, na qual a perfeição estética do corpo é supervalorizada, concepção essa reforçada pelas imagens modelos inatingíveis - veiculadas pelos meios de comunicação de massa e pela consequente lógica do consumo que se fortalece na cultura ocidental contemporânea.

\section{Discussão}

Considerando que a feminilidade advém da significação da castração (Souza, 2007), pode-se pensar que a beleza e os seus ideais, tão difundidos na cultura contemporânea, podem ter mais de uma função no psiquismo feminino.

Todas as mulheres, por estarem inseridas na cultura, têm como referência esses valores estéticos, isto é, esses padrões que apontam o que é uma mulher bela. Contudo, o que vai determinar qual função o ideal de beleza irá exercer sobre seu psiquismo está relacionado à sua experiência particular de constituição psíquica, isto é, à relação com as figuras parentais, à construção do seu eu ideal e posterior ideal de eu, à passagem pela castração e a sua elaboração.

Essa vivência singular parece ser determinante na forma de cada mulher se posicionar diante de sua própria imagem e no quanto e como se investe nessa imagem para que ela possa pronunciar-se como mulher.

Ao mesmo tempo, é importante ressaltar que a forma como elas se relacionam com o próprio corpo está atravessado também pela dimensão cultural, visto que "os corpos são produzidos pelas sociedades em uma dialética sujeito/cultura. (...) A experiência do corpo é sempre modificada pela experiência da cultura" (Novaes, 2006, p. 32).

Assim, por exemplo, a feiura-correspondente a tudo aquilo que foge dos ideais de beleza - tem um impacto sobre a imagem feminina em função de o discurso social dizer que uma mulher feia é menos feminina. Sendo a imagem das mulheres confundida com a de beleza, "um dos pontos mais enfatizados no discurso sobre a mulher (é): ela pode ser bonita, deve ser bonita, do contrário, não será totalmente mulher (Novaes, 2006, p. 85).

Dessa maneira, por um lado, pode-se pensar que as mulheres, ao servirem-se dos atributos e adereços que a cultura sinaliza como pertencentes ao ideal de beleza e, como aludido anteriormente, ao campo do feminino, estão conseguindo encontrar uma forma de elaborar a sua castração. No entanto, isso só se dá quando a sua relação com esses ideais é profícua, sem um sofrimento psíquico aprisionador na busca de se adequar a esses padrões estéticos.

É nesse sentido que Pommier (1991) afirma que a relação de toda mulher com a sua imagem possui alguns impasses. Alguns dos sinais que revelam feminilidade - o andar, a voz, o olhar, a postura - são universais e incontestáveis, contudo não a dotam de uma identidade feminina; por esse motivo, em busca desse saber, ela recorre a adornos que a tornem visível, "pois é assim que seu corpo, incompleto pela ausência de falo, adquire a necessária concretude para sua existência" (Freire, 2002, p. 73).

Ao se seguir essa premissa, viabiliza-se a eclosão de uma das dimensões próprias do feminino, que é um movimento de captura do olhar alheio. Como vimos neste estudo, desde a concepção freudiana, a representação do gênero feminino é dada pelo olhar desejante do outro. Dessa maneira, isso pode ser conquistado por meio da aparência bela, a qual, com seus recursos, possibilita a percepção do corpo da mulher.

Considerando que é no corpo que a mulher transportará a versão imaginária daquilo que Ihe falta (Jerusalinsky, 2000), o movimento de atrair o olhar do outro, como uma das 
saídas para a enigmática constituição da feminilidade, confere às mulheres uma garantia identitária, como se elas só pudessem se reconhecer por meio desse viés. Essa identidade pode ser alcançada, portanto, por meio da estética e de seus referenciais de beleza feminina, que utiliza recursos tais como maquiagem, joias, acessórios - em busca de imagem bela e atraente.

Nesse sentido, é na tentativa de estabelecer uma imagem idealizada perante o olhar do outro e de desfrutar das sensações corporais que o afetam "(...) que o sujeito feminino ganha corpo e se elabora. Diante do vazio e do desamparo que assola a sua existência, ele se manifesta e cria formas de existir" (Vieira, 2006, p. 110).

É importante elucidar que a castração, longe de ser reduzida ao temor de uma mutilação anatômica, é efetiva no instante em que o sujeito se depara com o desvio do desejo e do olhar materno para uma outra direção que não ele e seu corpo, a qual possibilita assinalar o mistério do falo (Pommier, 1991). Assim, para a mulher, investir no próprio corpo é uma forma de (re)significá-lo, de atribuir-lhe valor e de ludibriar a referência à castração.

Recorrer à beleza e a seus ideais pode ser compreendido como uma forma de as mulheres elaborarem a sua falta; os adereços, portanto, seriam complementos que contribuem para o processo de tornarse mulher, funcionando como compensação fálica.

Por outro lado, quando a relação com esses ideais se torna escravizante para a mulher, a beleza parece uma tentativa de encobrir essa falta "em uma franca recusa da castração" (Pimentel, 2008, p. 44). Nesse sentido, a busca por procedimentos para manter uma aparência jovem - ideal esse também enraizado na cultura ocidental - parece estar relacionada à dificuldade de se defrontar com a finitude humana, ou seja, com a impossibilidade de ser eterno.
A respeito disso, Freire (2002) ressalta: "A revolta diante da castração leva a menina a investir esse corpo como sendo o falo e o coloca (o corpo) em primeiro plano, tanto na teatralização de seus sintomas quanto no exibicionismo desse corpo" (p. 72).

No contexto atual, frente à emergência da estética do corpo como uma urgência feminina, pode-se supor que é algum tipo de conflito inconsciente que essas questões sinalizam. Em outras palavras:

\begin{abstract}
Uma determinada inquietude que parece revelar uma tensão, marcando o ser mulher, a partir do corpo esteticamente manipulado. Nesse movimento, o desejo de uma imagem idealizada de corpo parece se ancorar num grande impasse: um certo prazer em investir, através do real do corpo, nessa imagem desejada e uma inquietação por nunca alcançá-la plenamente, ou quem sabe, numa ordem inversa: uma inquietação que parece levar incessamente ao ato de investir, dessa forma, no próprio corpo (Souza, 2007, p. 16, itálicos do autor)
\end{abstract}

Para atender aos padrões de beleza atuais, as mulheres lançam-se em busca dos diferentes métodos estéticos, os quais se modificam e se sofisticam muito rápida e constantemente. Com isso, surge o corpo

(...) sugado pelas lipoaspirações, implantado
pelos silicones, preenchido por quantidade
de gordura, cortado pelos bisturis, espetado
pelas seringas com botox, diminuído
ou secado pelas dietas, apertado pelos
modernos espartilhos, mutilado por
novas técnicas cirúrgicas, modelado pelas
máquinas das academias e clínicas de
estética, manipulado, enfim... (Souza, 2007,
p. 15, itálicos do autor)

Diante disso, para se compreender o que está em jogo, alguns questionamentos se tornam tanto pertinentes quanto necessários: por que, por exemplo, as celulites, essas cavidades sobre a pele, são tão temidas pelas mulheres e devem ser eliminadas a qualquer preço? De quais buracos as celulites estão realmente falando? Por que preencher os sinais do corpo 
que revelam o envelhecimento? Por que o corpo, em sua totalidade, deve ser tão rijo?

Parece que aí há o que Souza abaliza: "uma eterna expectativa de reparar uma balança imaginária (...) que tenta remeter certo equilíbrio entre os excessos e as faltas simbólicas para o real de um corpo. E um corpo que possa ser reconhecido como sendo o de uma mulher" (2007, p. 70, itálicos do autor).

Ante a esse quadro, pode-se supor que, no caso dessas mulheres que se lançam em uma busca infindável por um padrão de beleza inatingível, o conflito inconsciente, aludido pela mesma autora anteriormente, está relacionado a uma falha na constituição do seu eu ideal, aquele instaurado na relação com a figura que desenvolveu a função materna no sujeito.

Nesse empenho em buscar a forma bela que a sociedade difunde como ideal, as mulheres tentam, dessa maneira, apresentar-se com uma imagem idealizada ao olhar dos outros, tendo em vista que este está representado inicialmente pelo olhar materno - o qual foi falho (Vieira, 2006).

Nesse sentido, elas acabam estabelecendo uma relação persecutória com o próprio corpo e sua imagem e lançam-se, sem medir esforços, à pretensão de corresponder aos padrões estéticos. Contudo, essa missão acaba sendo abortada, pois esse ideal escorregadio é impossível de ser alcançado em sua plenitude.

Como "o sujeito vê o seu ser numa reflexão ao outro, isto é, em relação ao Ich-Ideal" (Lacan, 1954/1998a, p. 148, itálicos do autor), sua imagem, portanto, é constituída a partir do discurso e do investimento libidinal materno, e, como há uma lacuna na constituição do seu eu ideal, ele não conseguirá se apropriar satisfatoriamente de sua imagem.

Isso pode trazer como efeito o que vem sendo discutido: deixar o próprio corpo à mercê do imperativo da perfeição estética como condição fundamental para ser feliz (Pimentel, 2008).

A insatisfação crônica com a imagem corporal ocorre porque, em vez de ser um complemento ao ser feminino (elementar), o investimento no embelezar-se acaba sendo tomado como um compromisso obrigatório. Há uma inversão importante aí: de complemento, a busca pelo ideal se torna condição (ilusória) de completude, e o sujeito perde para ele o estatuto de elementar.

Enfim, se houve uma falha na constituição do eu ideal da mulher, o ideal de eu sofrerá os efeitos disso, visto que ele é um desdobramento do eu ideal e corresponde aos ideais culturais. Sendo o ideal de beleza obstinadamente difundido na cultura, a relação da mulher com esse ideal estará diretamente relacionada à instituição de seu eu ideal. Dessa forma, havendo uma deficiência naquele período inicial, essa situação poderá se repetir na forma como ela se coloca frente a esses padrões: por mais que ela se esforce, os resultados serão sempre insuficientes, frente à falta de investimento narcísico que o agente materno inscreveu em seu corpo.

\section{Considerações finais}

Como a construção do corpo, segundo a concepção tomada neste artigo, está atravessada pela dimensão cultural, é importante salientar que o culto à beleza passa a se relacionar com outros fenômenos muito expressivos na contemporaneidade.

Pode-se dizer que um deles é o consumismo. Em busca dos ideais de beleza, muitas mulheres acabam entrando nesse sedutor campo e são estimuladas a adquirir produtos, roupas, sapatos, acessórios, bolsas, maquiagens ou a submeter-se a intervenções estéticas como cirurgias plásticas, próteses de silicone e aplicação de botox, dentre muitas outras, ou seja, elas são seduzidas e atraídas para, posteriormente, seduzirem e atraírem. 
No entanto, cabe ressaltar que a questão aqui não está no simples fato de consumir, pois desfrutar de tudo isso que socialmente é oferecido às mulheres pode, como já aludido, ser uma forma de garantia identitária na constituição da feminilidade.

A questão que merece destaque e um olhar crítico é o fato de entrar em jogo uma relação desenfreada, sem limites, como se a única forma de felicidade fosse poder consumir e, assim, corresponder aos padrões estéticos.

Nesse sentido, absolutamente relacionada com o fenômeno do consumismo, está a influência da mídia na transmissão e na manutenção dos ideais de beleza femininos. Direta ou indiretamente, os diferentes meios que a constituem acabam veiculando valores que, aos poucos, se tornam absolutos e incontestáveis.

Esses meios de comunicação, pelo estatuto atribuído na cultura, acabam sendo influentes no processo de subjetivação, certamente não apenas das mulheres, mas de todos os que se acham nela inseridos, anunciando seus produtos como promessa ilusória de felicidade e plenitude.

Dessa maneira, não poder obter esses produtos nem satisfazer aos ideais estéticos sinalizados pela cultura coloca essas mulheres em uma significativa condição de sofrimento psíquico. Além disso, conforme Novaes (2006) são culpabilizadas por sua situação, já que o que elas desejam é, supostamente, acessível, basta apenas se esforçarem para obter o que desejam ou para alcançar determinada aparência.

Já que o ideal é da ordem do inatingível, funda-se um ciclo gerador de constante insatisfação e frustração, e a feiura - em geral - acaba se tornando "fruto de uma exclusão sem culpa", como diz Novaes (2006, p. 251), o que estimula as mulheres a travarem uma angustiada batalha contra suas próprias imagens.

É importante interrogar, como afirma Armênio, se o corpo feminino, que deve ser jovem, belo e magro, pode estar sinalizando "uma subtração das marcas históricas, da expressividade e das marcas femininas" (2008, p. 112). Isso vai ao encontro com o que Moreno (2008) coloca, que o corpo das mulheres passou de um sinuoso $S$ à magreza e à postura de um I, isto é, uniformizado, sem expressão de marcas singulares.

Enfim, pode-se pensar que essa uniformização também diz respeito a uma tentativa de uniformização subjetiva da mulher, que, em vez de oferecer uma via de identidade, acaba inviabilizando-a pela permanente insatisfação.

Heloisa Cardoso da Silva

Pós-graduanda, Psicóloga clínica na Central Clin em Torres, Rio Grande do Sul - RS - Brasil.

E-mail: helo-cardoso@hotmail.com

\section{Siloé Rey}

Psicóloga. Psicanalista. Mestre em Psicologia Social pela PUCRS. Professora do Curso de Psicologia da Universidade Luterana do Brasil, Torres - RS - Brasil.

E-mail: siloe.rey@gmail.com

Endereço para envio de correspondência:

Rua Firmino Paim, 865 Bairro Getúlio Vargas Torres, RS CEP: 95560-000

Recebido 10/8/2010, Aprovado 16/5/2011. 


\section{Referências}

Armênio, E. (2008). A estética da magreza. In S. L. Alonso, D. M. Breyton, \& H. M. Albuquerque (Org.), Interlocuções sobre o feminino na clínica, na teoria, na cultura (pp. 110-121). São Paulo: Escuta.

Del Priori, M. (2009). Corpo a corpo com a mulher. Pequena história das transformações do corpo feminino no Brasil (2a ed.). São Paulo: SENAC São Paulo.

Dor, J. (2003). Introdução à leitura de Lacan: o inconsciente estruturado como linguagem. Porto Alegre: Artmed.

Fernandes, M. H. (2008). Corpo. Clínica psicanalítica (3a ed). São Paulo: Casa do Psicólogo.

Freire, L. (2002). A histeria e a beleza: uma expressão no contexto cultural da atualidade. Psicologia: Ciência e Profissão, 22(3), 70-77.

Freud, S. (2004). À guisa de introdução ao narcisismo. In Edição standard brasileira das obras psicológicas completas de Sigmund Freud (L. A. Hanns, trad., Vol. 1, pp. 95-131) Rio de Janeiro: Imago (Trabalho original publicado em 1914).

Freud, S. (2006a). Três ensaios sobre a teoria da sexualidade. In Edição standard brasileira das obras psicológicas completas de Sigmund Freud (J. Salomão, trad., Vol. 7, pp. 119-217). Rio de Janeiro: Imago (Trabalho original publicado em 1905).

Freud, S. (2006b). A organização genital infantil: uma interpolação na teoria da sexualidade. In Edição standard brasileira das obras psicológicas completas de Sigmund Freud (J. Salomão, trad., Vol. 19, pp. 155-161). Rio de Janeiro: Imago (Trabalho original publicado em 1923).

Freud, S. (2006c). A dissolução do complexo de Édipo. In Edição standard brasileira das obras psicológicas completas de Sigmund Freud (J. Salomão, trad., Vol. 19, pp. 191-199). Rio de Janeiro: Imago (Trabalho original publicado em 1924).

Freud, S. (2006d). Algumas consequências psíquicas da distinção anatômica entre os sexos. In Edição standard brasileira das obras psicológicas completas de Sigmund Freud (J. Salomão, trad., Vol. 19, pp. 273-286). Rio de Janeiro: Imago (Trabalho original publicado em 1925).

Freud, S. (2006e). Sexualidade feminina. In Edição standard brasileira das obras psicológicas completas de Sigmund Freud (J. Salomão, trad., Vol. 21, pp. 231-251). Rio de Janeiro: Imago (Trabalho original publicado em 1931).

Freud, S. (2006f). A feminilidade. In Edição standard brasileira das obras psicológicas completas de Sigmund Freud (J. Salomão, trad., Vol. 22, pp. 113-134). Rio de Janeiro: Imago (Trabalho original publicado em 1932).

Garcia-Roza, L. A. (2008). Introdução à metapsicologia freudiana. Artigos de metapsicologia: narcisismo, pulsão, recalque, inconsciente (7a ed., Vol. 3). Rio de Janeiro: Jorge Zahar.

Gil, A. C. (2010). Como elaborar projetos de pesquisa (5a ed.). São Paulo: Atlas.

Godoi, M. R. (2006). Mídia magazine e narcisismo produtivo: investidas cultural e econômica sobre a masculinidade na contemporaneidade capitalista. Dissertação de mestrado, Instituto de Linguagens, Universidade Federal de Mato Grosso, Cuiabá

Jerusalinsky, A. (2000). O desejo paterno. Correio da APPOA. Freud e o homem Moisés, 79, 31-39.
Lacan (1998a). Os escritos técnicos de Freud (V. Ribeiro, trad., Livro 1). Rio de Janeiro: Jorge Zahar (Trabalho original publicado em 1954).

Lacan, J. (1998b). As psicoses (V. Ribeiro, trad., Livro 3). Rio de Janeiro: Jorge Zahar (Trabalho original publicado em 1956).

Lacan, J. (1998c). As formações do inconsciente (V. Ribeiro, trad., Livro 5). Rio de Janeiro: Jorge Zahar (Trabalho original publicado em 1958).

Lima, G. G. de. (2006). De mãe a mulher: os circuitos do amor, desejo e gozo. Tese de doutorado, Instituto de Psicologia, Universidade de São Paulo, São Paulo.

Mezan, R. (1994). Pesquisa teórica em psicanálise. Psicanálise e Universidade, 2, 51-75.

Moreno, R. (2008). A beleza impossível. Mulher, mídia e consumo. São Paulo: Ágora.

Novaes, J. V. (2006). O intolerável peso da feiura. Sobre as mulheres e seus corpos. Rio de Janeiro: PUC-Rio/Garamond.

Nunes, S. A. (2002). O feminino e seus destinos. In J. Birman (Org.), Feminilidades (pp. 35-57). Rio de Janeiro: Contra Capa Livraria.

Pimentel, D. (2008). Beleza pura. Estudos de Psicanálise, 31, 43-49.

Poli, M. C. (2007). Feminino/masculino. Rio de Janeiro: Jorge Zahar.

Pommier, G. (1991). A exceção feminina. Os impasses do gozo (2a ed.). Rio de Janeiro: Jorge Zahar.

Ramalho, R. R. (2001). Uma melancolia tipicamente feminina. Revista da Associação Psicanalítica de Porto Alegre. A clínica da melancolia e as depressões, 20, 37-55.

Sant'Anna, D. B. (2001). Corpos de passagem. Ensaios sobre a subjetividade contemporânea. São Paulo: Estação Liberdade.

Silva, D. Q. da, \& Folberg, M. N. (2008). De Freud a Lacan: as ideias sobre a feminilidade e a sexualidade feminina. Estudos de Psicanálise, 31, 50-58

Sociedade Brasileira de Cirurgia Plástica - SBCP. (2009, janeiro). Cirurgia plástica no Brasil. Pesquisa realizada pelo Instituto Datafolha. Recuperado em 15 setembro 2009 do site da SBCP:http://www.cirurgiaplastica.org.br/publico/ pesquisa2009.ppt.

Souza, K. C. V. de. (2007). O feminino na estética do corpo: uma leitura psicanalítica. Dissertação de mestrado, Pró-Reitoria de Pesquisa e Pós-Graduação, Universidade Católica de Pernambuco, Recife.

Valdivia, O. B. (1997). Psicanálise e feminilidade: algumas considerações. Psicologia: Ciência e Profissão, 17(3), 20-27.

Vieira, K. M. F. (2006). O corpo da mulher em correção: subjetividade e cirurgia estética. Dissertação de mestrado, Programa de Pós-Graduação em Psicologia, Universidade de Fortaleza - UNIFOR, Fortaleza, CE.

Vilhena, J., Medeiros, S. A., \& Novaes, J. V. (2005). Violência da imagem: estética, feminino e contemporaneidade. Revista Mal-Estar e Subjetividade, 5(1), 109-144. 